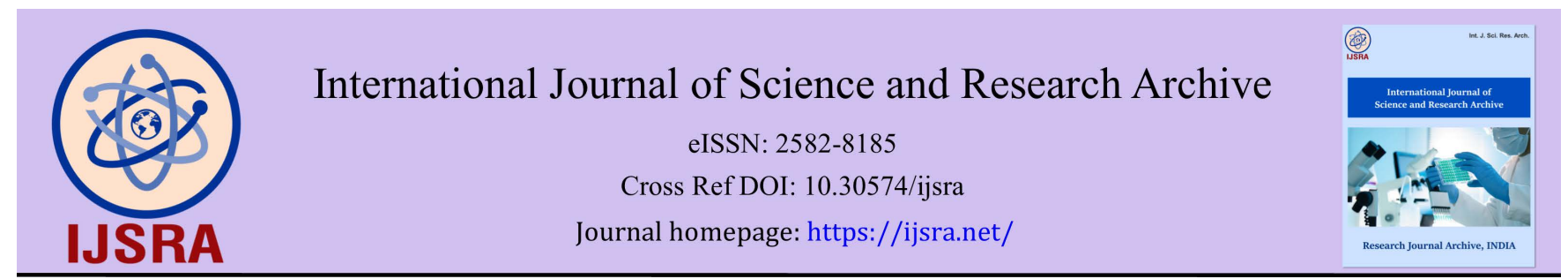

(RESEARCH ARTicle)

\title{
IOT-based biometric attendance system for CRUTECH
}

\author{
Prince Ana ${ }^{1,}{ }^{*}$, Ukoette Jeremiah Ekah ${ }^{2}$ and Emmanuel Oyo-Ita ${ }^{1}$ \\ ${ }^{1}$ Department of Computer Science, Cross River University of Technology, Calabar, Nigeria. \\ 2 Department of Physics, Cross River University of Technology, Calabar, Nigeria.
}

International Journal of Science and Research Archive, 2022, 05(01), 039-050

Publication history: Received on 25 December 2021; revised on 29 January 2022; accepted on 30 January 2022

Article DOI: https://doi.org/10.30574/ijsra.2022.5.1.0035

\begin{abstract}
Identification of students in higher institutions in Nigeria, coupled with the recent insecurity and impersonation in the country has exposed the need to find a way to identify each and every person in the institution and Cross River University of Technology (CRUTECH), Calabar, Nigeria, is not an exception. The current method of identifying students with an identification card is vulnerable to abuse. To curtail this menace, this research proposes an IOT-based attendance system using ESP32 microcontroller, 0.96" OLED display and R305 fingerprint module. During operation, the system collects the fingerprint data from multiple users through the microcontroller based on ESP32 Wi-Fi enabled module and sends it over the internet to a website. Enrollment of fingerprints is done on the server using the interfaced fingerprint sensor module. Verification of user's fingerprint is done on the webserver while fingerprint templates are transmitted over Wi-Fi. The website user interface (UI) used in this project is developed using PHP, CSS and JavaScript. It has a database and records of attendance. By logging into the website, attendance records of each user, including personal details as well as incoming and outgoing time can be collected. This data can be downloaded and exported to an excel sheet for evaluation.
\end{abstract}

Keywords: Attendance system; Internet of things; CRUTECH; Biometric; ESP 32 microcontroller

\section{Introduction}

The method of identifying students in institutions in Nigeria is by registration numbers, students' identity (ID) cards, fee clearance cards, photo cards, among others, but with its inherent problems. Sometimes, the cards are stolen, forgotten at home, misplaced, mutilated, transferred or faked [1]. Some institutions, in a way to identifying their students, in order to combat theft or security issues, have introduced other methods like the use of username, Personal Identity Numbers (PINs), passwords, secret codes or tokens to gain access to some buildings. The problem of insecurity still persist because these methods are compromised by students and usually, they are forgotten, shared, guessed, lost or stolen and they can be cracked by intercepting the presentation of such passwords or by brute force attacks. In addition, tokens could be cracked by robbing, copying or simulating them [2].

A controlled environment is critical to institutions [3][4] and to provide a safe and secure environment on campus, biometric security system is key. Biometric security systems are unique to each person, permanent, fast, accurate, not subjected to change and impossible to forge [5]. Therefore, biometric enrollment for students will cut down on illegal activities within the campus since each person is identified distinctively. This should be done immediately the student is offered admission into the tertiary institution and shall be used throughout the student's period in school. Biometric security should be used to authenticate student's access to libraries, hostels, course registrations, classrooms for lectures and examinations. This will tackle truancy, eliminate identity fraud, verify students' activities within the campus and curb examination malpractices. Access to campuses should be permitted only to authorized people, as

\footnotetext{
* Corresponding author: P Ana

Department of Computer Science, Cross River University of Technology, Calabar, Nigeria.

Copyright $(2022$ Author(s) retain the copyright of this article. This article is published under the terms of the Creative Commons Attribution Liscense 4.0.
} 
students, staff and recurring visitors should be accurately time-stamped and identified, creating an irrefutable record of one's total activities within the campus. This will guarantee safety and the potential security breach that puts student's lives in danger will be eliminated. It will also improve seriousness in studies, as students' activities can be monitored.

Various researchers in academic and industries have developed biometric identity system using face, iris and fingerprint [6-25]. The nexus of this research is to design, construct and implement an IOT-based biometric system with a view to curbing insecurity in Cross River University of Technology, Calabar and other institutions in Nigeria.

\section{Material}

\subsection{Technology/Software Used}

In order to achieve this project, various technology/software were used, each having its specific functions towards the development of this system. Some of these technology/software used to develop the user interface include:

- $\quad$ Embedded C: All the hardware interface coding is done in embedded C Language.

- $\quad$ PHP: All the Logics and web interface is written in PHP Language.

- MYSQL: For database, MYSQL database is used.

- $\quad$ Apache 2: The web interface was run over Apache 2 server.

- JavaScript and CSS: Used to style web Interface with animation and validation of the form.

\subsection{Hardware Used}

The major hardware components used in the development of this system are discussed below:

\subsubsection{ESP32 Wi-Fi Module}

Fig 3.1 shows ESP32 low-cost Wi-Fi controller board. It is an open-source platform used for building Wi-Fi based electronic projects. The ESP32 Wi-Fi is a miniature wireless $802.11 \mathrm{Wi}-\mathrm{Fi}$ microcontroller development board. It turns the very popular ESP8266 wireless microcontroller module into a fully-fledged development board. Programming the ESP module is as simple as programming any other microcontroller device, as the module includes a built in micro-USB interface, allowing the module to be programmed directly from the Arduino Integrated Development Environment (IDE).

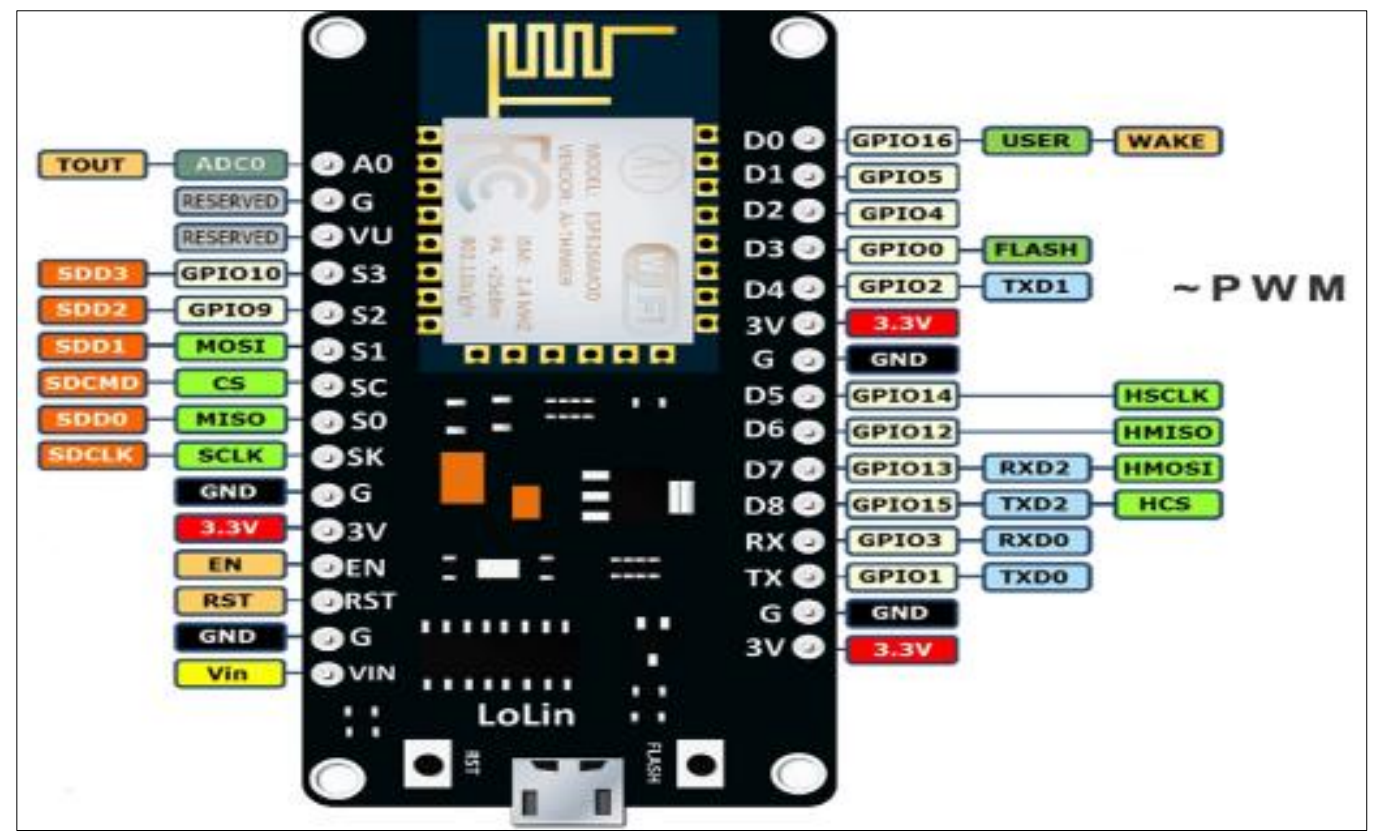

Figure 1 ESP32 Wi-Fi Controller Board 
The ESP32 microcontroller integrates a Tensilica L106 32-bit reduced instruction computer (RISC) processor which achieves extra-low power consumption and reaches a maximum clock speed of $160 \mathrm{MHz}$. The Real-Time Operating System (RTOS) and Wi-Fi stack allows about $80 \%$ of the processing power to be available for user application, programming and development. This miniature development board is capable of functioning consistently in industrial environments due to its wide operating temperature range. With highly-integrated on-chip features and minimal external discrete component count, the chip offers reliability, compactness and robustness.

\subsubsection{MT3608 DC To DC Step Up Boost Converter Module}

The MT3608 step-up booster converter module is a small sized highly efficient and low-cost dc-to-dc converter module built for converting or boosting dc voltage as low as $2 \mathrm{~V}$ to maximum $28 \mathrm{~V}$ dc with a maximum output current of $2 \mathrm{~A}$. The output voltage can be adjusted using the variable resistor used in the module.

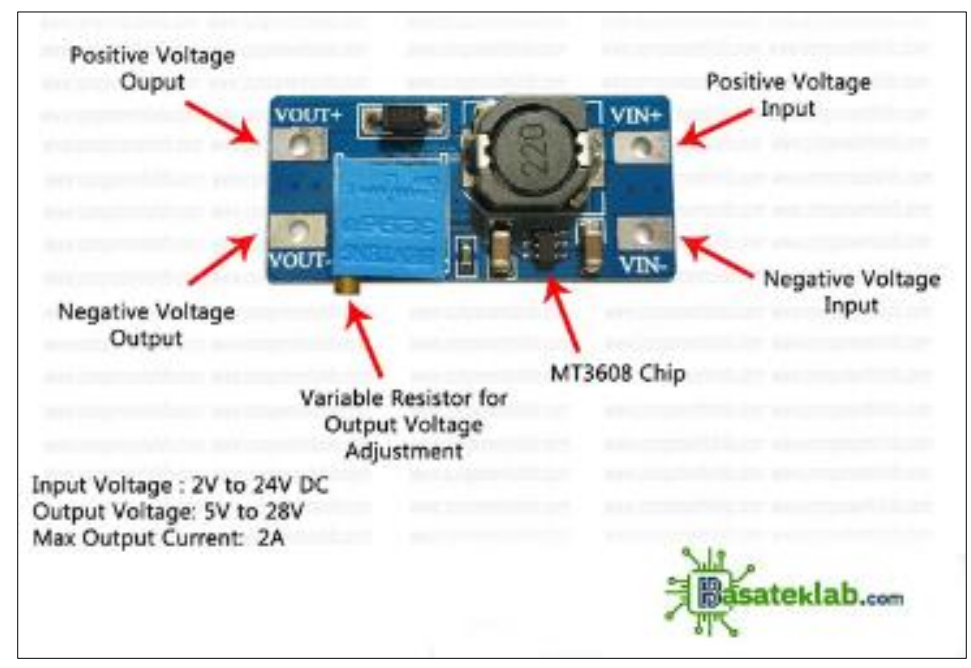

Figure 2 MT3608 DC To DC Step Up Boost Converter Module

The main component of this module is MT3608 IC. It is a highly efficient voltage booster IC with many in-built features like over heat protection, low quiescent current, soft start function, low external components and overheat shutdown. Other components used in this module are two ceramic capacitors, a variable resistor, a fixed resistor, a schottky diode and a $22 \mu \mathrm{H}$ inductor.

\subsubsection{TP4056 3.7V Li-ion 18650 Battery Charger Module}

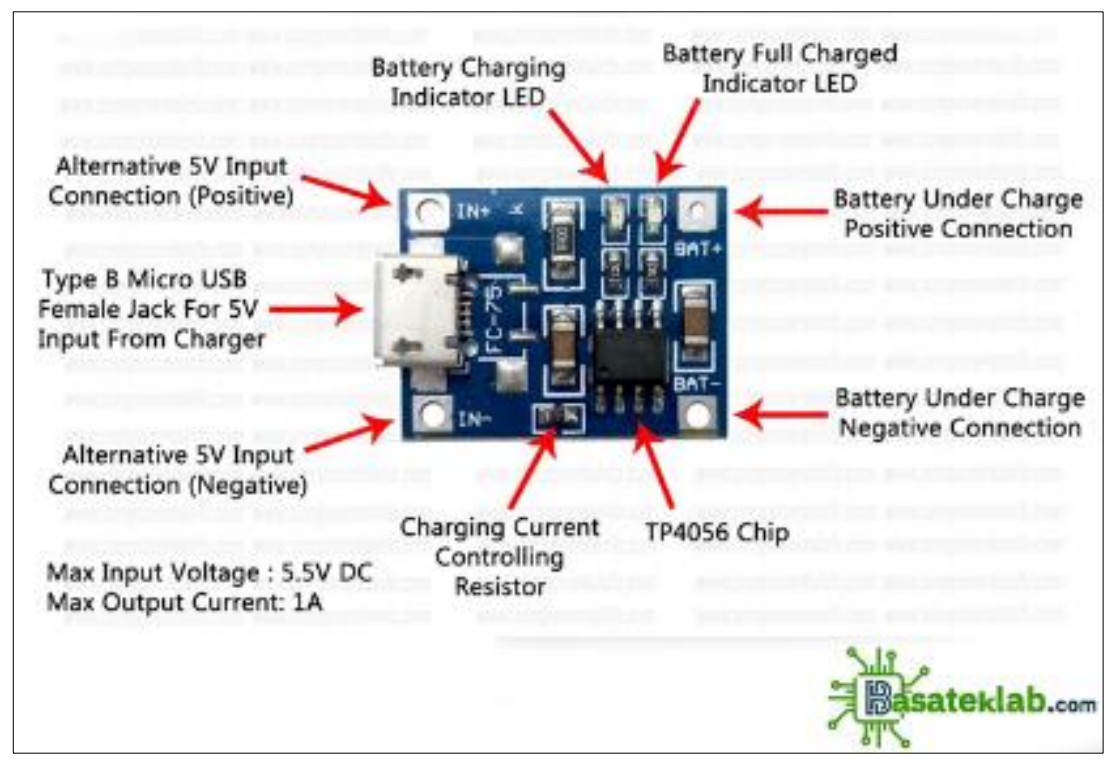

Figure 3 TP4056 3.7V Li-ion 18650 Battery Charger Module 
TP4056 module is an efficient 3.7V single Li-ion cell charging module. It can not only charge 18650 cells but a wide variety of different sizes and kinds of 3.7V Li-ion batteries. In the heart of this module lies a TP4056 IC, an advanced lithium battery charging IC. The IC is built and internally programmed to provide efficient charging to a Li-ion cell which increases the cell back-up and life.

This IC also has a temperature input pin from which it can be connected to an NTC temperature sensor. The IC is also programmed to disconnect the charging when the battery temperature goes above the IC's programmed limit. The module has two LED indicators. One LED indicates the battery charging in progress and when the battery becomes fully charged, it automatically gets deactivated and the other LED becomes activated to indicate that the battery is fully charged.

\subsection{6" I2C OLED (Organic Light-Emitting Diode) Display Module}

An OLED is electroluminescent and therefore, emits its own light. Its display has high contrast and extremely wide viewing angle. It offers low power consumption and high readability. On average the display uses about $20 \mathrm{~mA}$ current, although it depends on how much of the display is switched on.

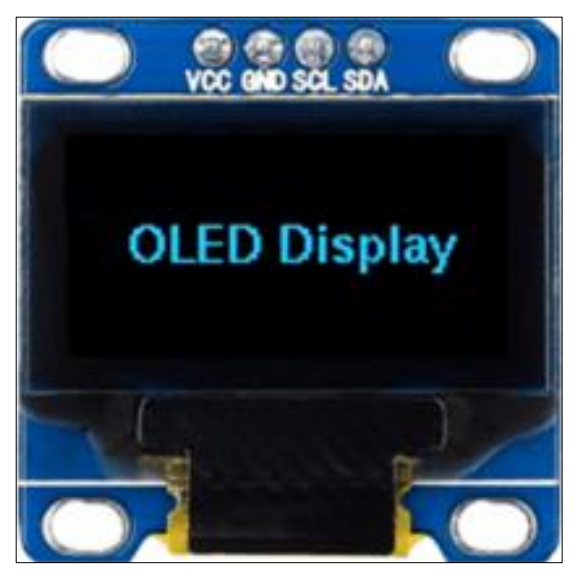

Figure 4 Pinout Diagram of OLED display

At the heart of the module is a powerful single-chip CMOS OLED driver controller - SSD1306. It can communicate with the microcontroller in multiple ways including I2C and SPI. SPI is generally faster than I2C but requires more I/O pins while I2C requires only two pins and can be shared with other I2C peripherals. It's a trade-off between pins and speed. The operating voltage of the SSD1306 controller is from $1.65 \mathrm{~V}$ to $3.3 \mathrm{~V}$ while OLED panel requires $7 \mathrm{~V}$ to $15 \mathrm{~V}$ supply voltage. All the different power requirements are sufficed using internal charge pump circuitry. This makes it possible to connect it easily to any $5 \mathrm{~V}$ logic microcontroller without using any logic level converter.

\subsubsection{R305 Finger Print Sensor}

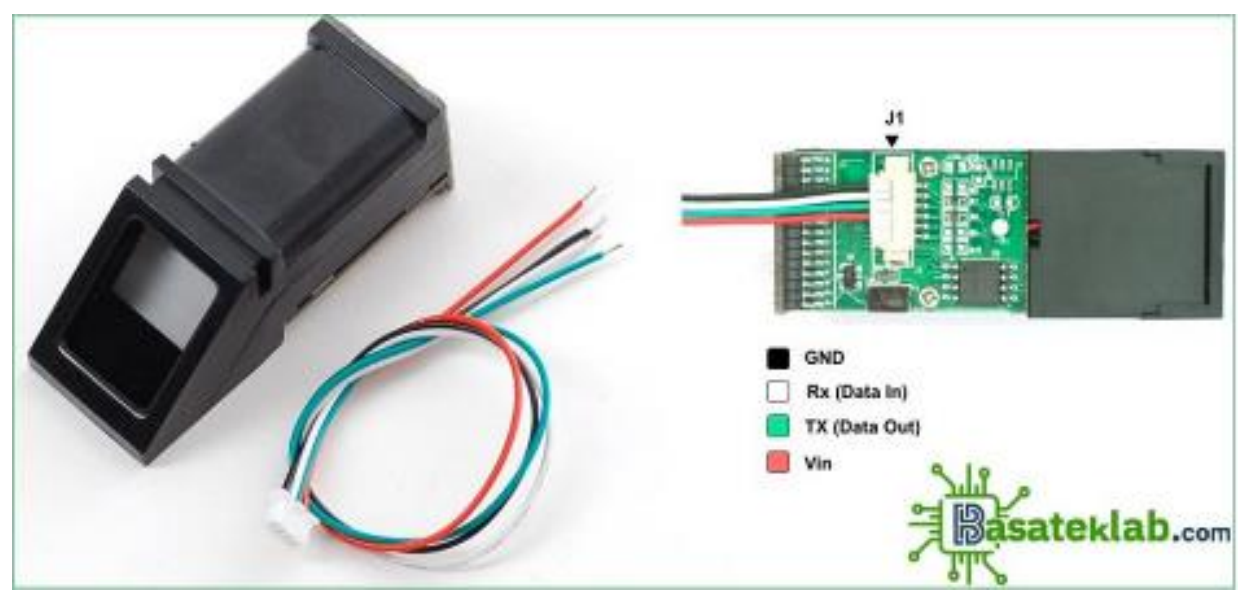

Figure 5 R305 fingerprint sensor and its pin connection 
R305 finger print sensor is a finger print sensor module with TTL UART interface. The user can store the fingerprint data in the module and can be configured in 1:1 or 1: $\mathrm{N}$ mode for identifying the finger print image of a person. The finger print module can directly interface with $3 \mathrm{v} 3$ or $5 \mathrm{v}$ microcontroller. A level converter (like MAX232) is required to interface with a PC.

This optical fingerprint reader uses high powered DSP chip AS601 form Synochip, that does the image rendering, calculation, feature finding and searching. It provides TTL serial out hence we can connect to any microcontroller or system. The DSP processor has on board flash memory which can store many finger prints.

\section{Methodology}

The Figure below shows block diagram of the finger print based biometric attendance management system. In the development of this system, a simplified approach of combining software and hardware was adopted. Here, ESP32 wireless 802.11 (Wi-Fi) microcontroller development board have been used for the monitoring and collection of user attendance data as well as wireless communication. The ESP32 module allows the user interact with the system and remotely sends collected user data to a database using customized web App developed with PHP.

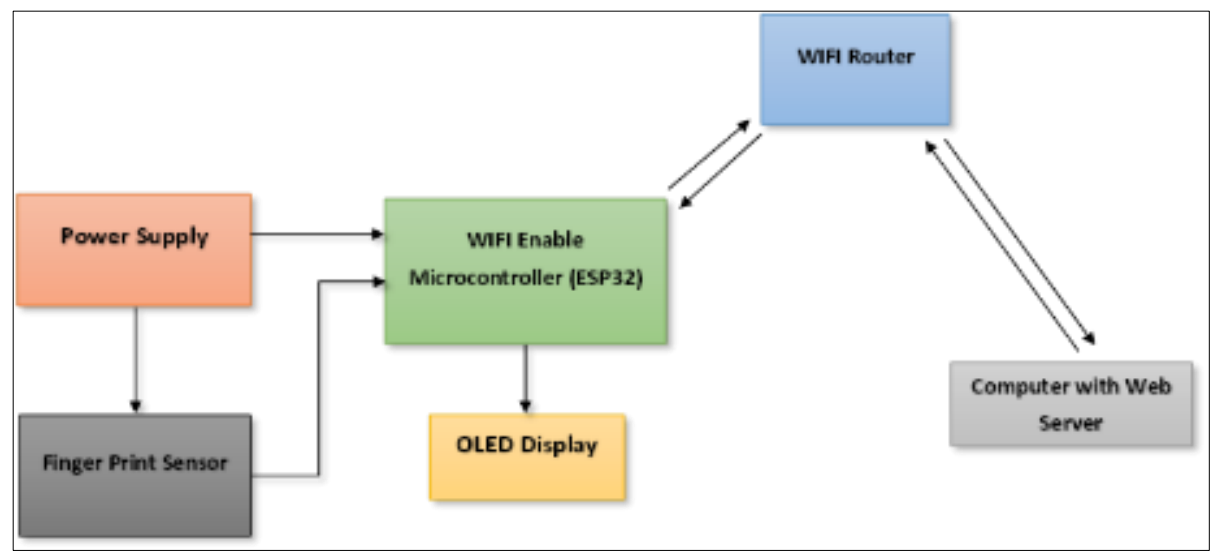

Figure 6 Design Block diagram of Microcontroller base attendance and monitoring system

The enrolment process is carried out by an administrator in the attendance system web portal. During authentication, the biometrics of the user is captured and the extracted features are compared (using a matching algorithm) with the ones already existing in the database to determine a match. The system consists of four major blocks; the power supply unit, the fingerprint module which captures the image, a microcontroller which collects the fingerprint data and the OLED display that displays the authentication information. Other design blocks include the Wi-Fi router, the computer with the hosting webserver and the user interface made up of PHP web App. The function of the computer is to store and keep track record of user fingerprint data, date and time of attendance in the system. As shown in the block diagram, the ESP32 is the main component of this system, it is responsible for the control of the entire system. It controls and manages all processes of the system. The finger print module is used for the collection of user finger print data, the OLED display gives visual indication, show resultant messages and instruct users on what is going on in the system.

\subsection{Circuit Description}

The figure below shows a complete circuit diagram of a biometric fingerprint-based attendance and monitoring system. At the heart of the system is ESP32 Wi-Fi supported microcontroller. The OLED display and fingerprint sensor is interfaced to the ESP32 board. The ESP32 controls and communicate with the fingerprint sensor and the OLED display.

The I2C pins of OLED display, SDA and SCL is connected to ESP32 port pins D21 \& D22 pins respectively. Similarly, fingerprint sensor modules Rx and Tx connects to the UART pins D17 and D18 of ESP32 module. This connection is used for serial communication between the ESP32 module and the sensor. Connection to the ESP32 microcontroller in this mode allows for the implementation of software serial during the programing of the system. Power for the system is supplied by $3.7 \mathrm{~V} \mathrm{Li}$-ion battery, whose output is stepped up to $+5 \mathrm{~V}$ DC by an onboard voltage regulator based on MT3608 DC to DC step up boost converter module. The $+5 \mathrm{~V}$ output from the boost converter module is then fed to the ESP32 module and the rest of the circuit components including the finger print module and the OLED display. Charging feature and voltage is provided by a 5V DC supply. This supply is then fed to the TP4056 3.7V Li-ion 18650 battery 
charging module via USB connection or a cable. This module provides the required charging procedure for the Li-ion battery which makes the battery life longer and charges it effectively.

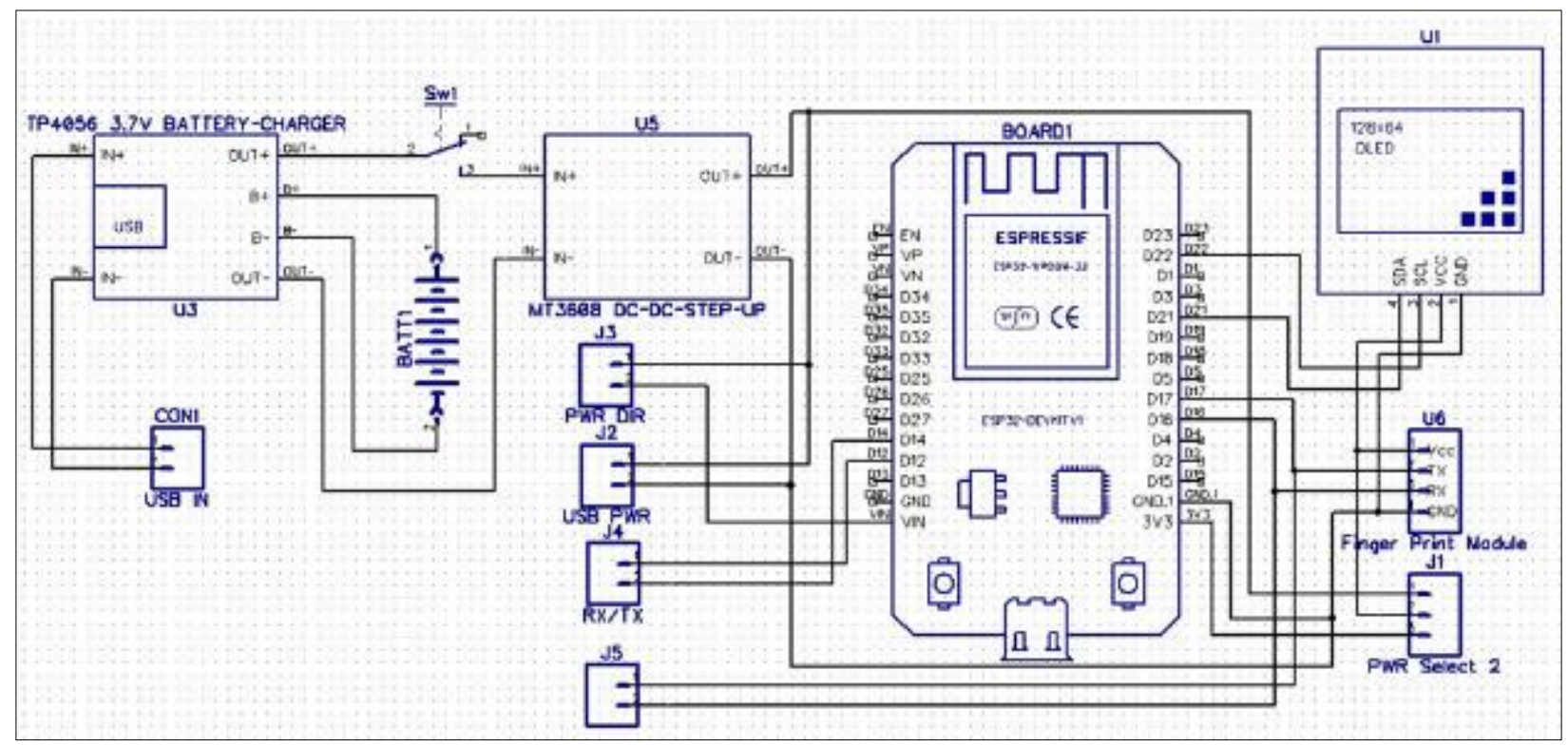

Figure 7 Complete Circuit Diagram of Fingerprint-Based Attendance and Monitoring System

\subsection{Construction}

The implementation of this system begins with the planning of the project followed by the design of the schematic diagram. This was done with the help of a Circuit Aided Design (CAD) program. Designing the schematic diagram using CAD program helps in demonstrating how the project would look like in the physical state, after which, it was converted to a Printed Circuit Board (PCB). The making of the PCB was done immediately after the design of the actual schematic. The building of the final prototype which commenced with the building and mounting of all the components was then carried out, leading to the completion of the prototype being described here.

To develop the hardware, four different approaches were used. The first approach was mounting and soldering of all the electronic components on the premade PCB. The second approach was setting up and configuring of the website user interface. The third approach was programming of the system and the fourth and final approach was testing of the fully functional prototype. In this section each of the approach will be considered and discussed in detail.

\subsection{Mounting and Soldering}

The jumper wires and resistors were first inserted with utmost care in their correct position. In identifying the resistors, a digital multimeter was used in checking each resistor before being installed. Next, the diodes in the power supply were installed, taking cognizance of their orientation.

The ICs were mounted next, with their orientation being observed to avoid circuit malfunctioning and possible damage of the ICs, especially the microcontrollers, followed by the capacitors. The electrolytic types were oriented as shown in the layout diagram above. The 3-terminal regulator was mounted on the PCB, with its leads bent in such a way that it fits into the holes provided on the PCB. 


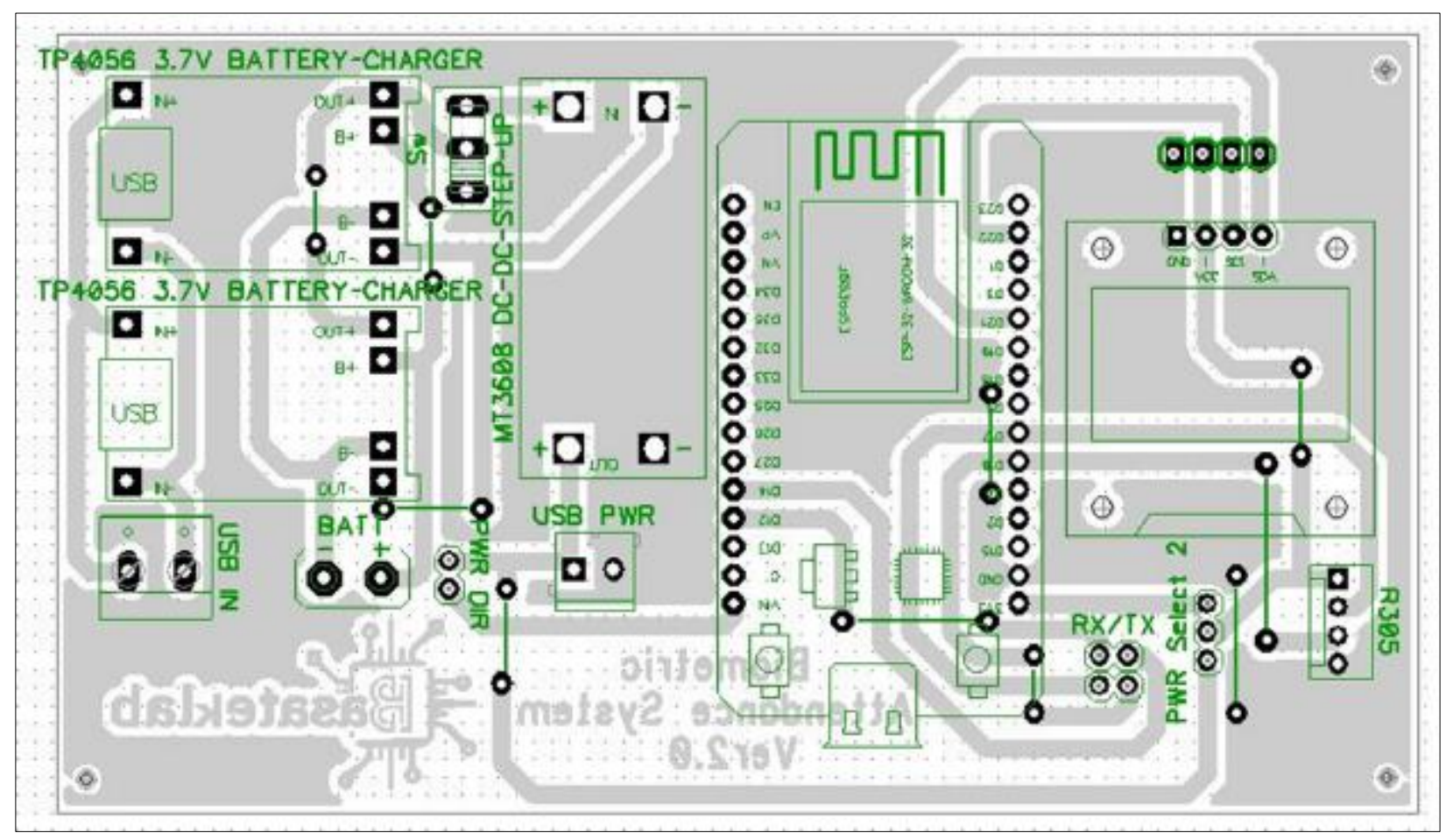

Figure 8 Layout Diagram of fingerprint-based attendance system

\subsection{Setting up Website Interface and Configuring of Database}

In setting up the Attendance web App (website Interface), a virtual web server application Wamp was first downloaded and installed. after completing the installation. The attendance web App folder was uploaded to the webserver ( $\mathrm{C}: \backslash$ wamp64\www), This is the location of the website in the C drive of the system where the webserver is installed.

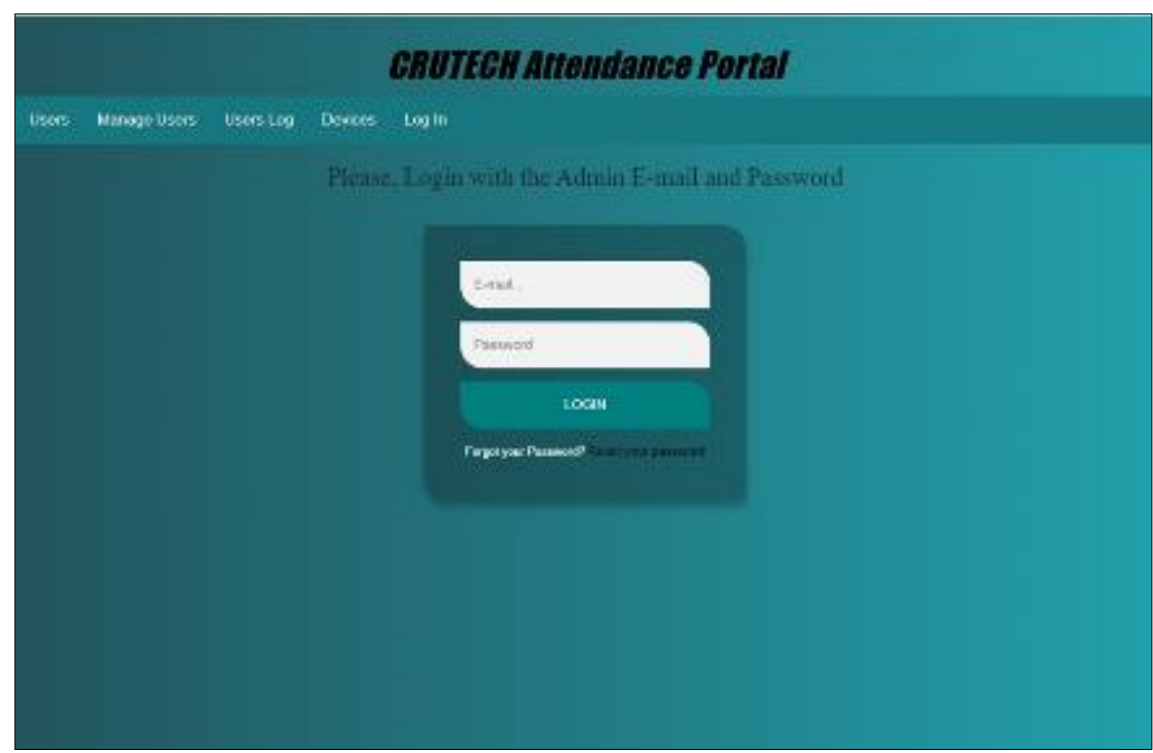

Figure 9 Biometric Attendance System showing Admin Login Screen

Next step was to create a database and connect the attendance web App. After creating and connecting the database to the web App, a browser was opened and the URL "http://www.portal.crutechattendance.com/biometricattendancev2". Launched. Doing this displays the admin login panel as shown above. From the admin panel, administrators can add new users, update and remove users using the user management system. Additionally, the administrator can view all attendance records. 


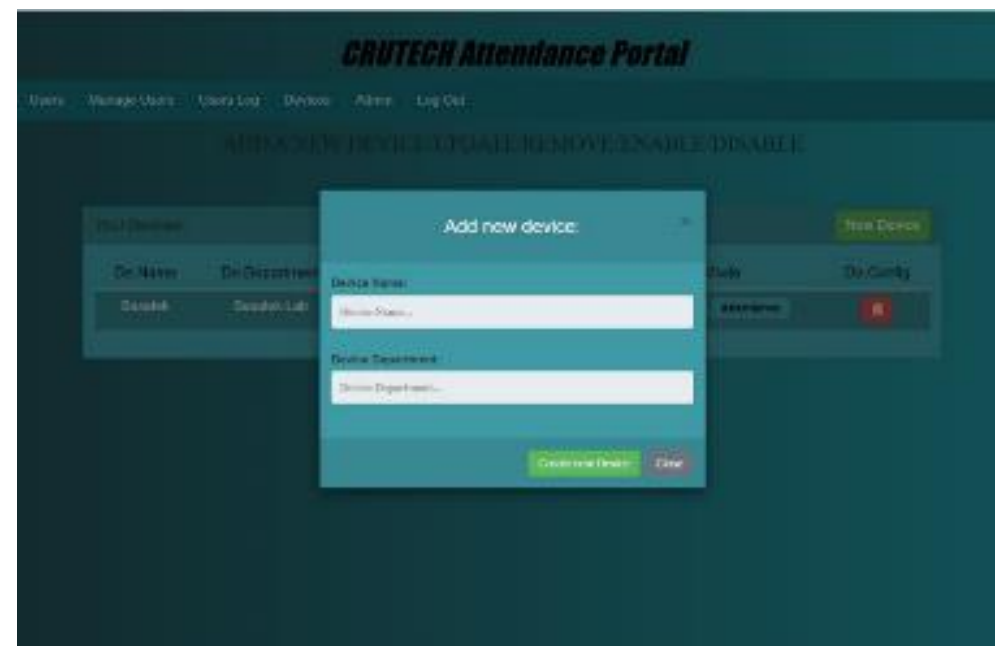

Figure 10 Biometric Attendance System showing Addition of New Device

From the device section, administrators can add, update, and remove device. To add a new device, the administrator needs to enter the device name and its department. Additionally, device token can be updated from the device section.

\subsection{Programming of the system}

Below is the screen shot of the application used in writing the system software. Here, Arduino Integrated Development Environment (IDE) was used in writing the required firmware for the controllers. The finger print attendance system intelligence and other supporting features are implemented in the firmware program of the ESP modules. The firmware program allows the system to take fingerprint data, compare to see if it matches with any data available in the database before authenticating the user and displaying the result on the OLED display.

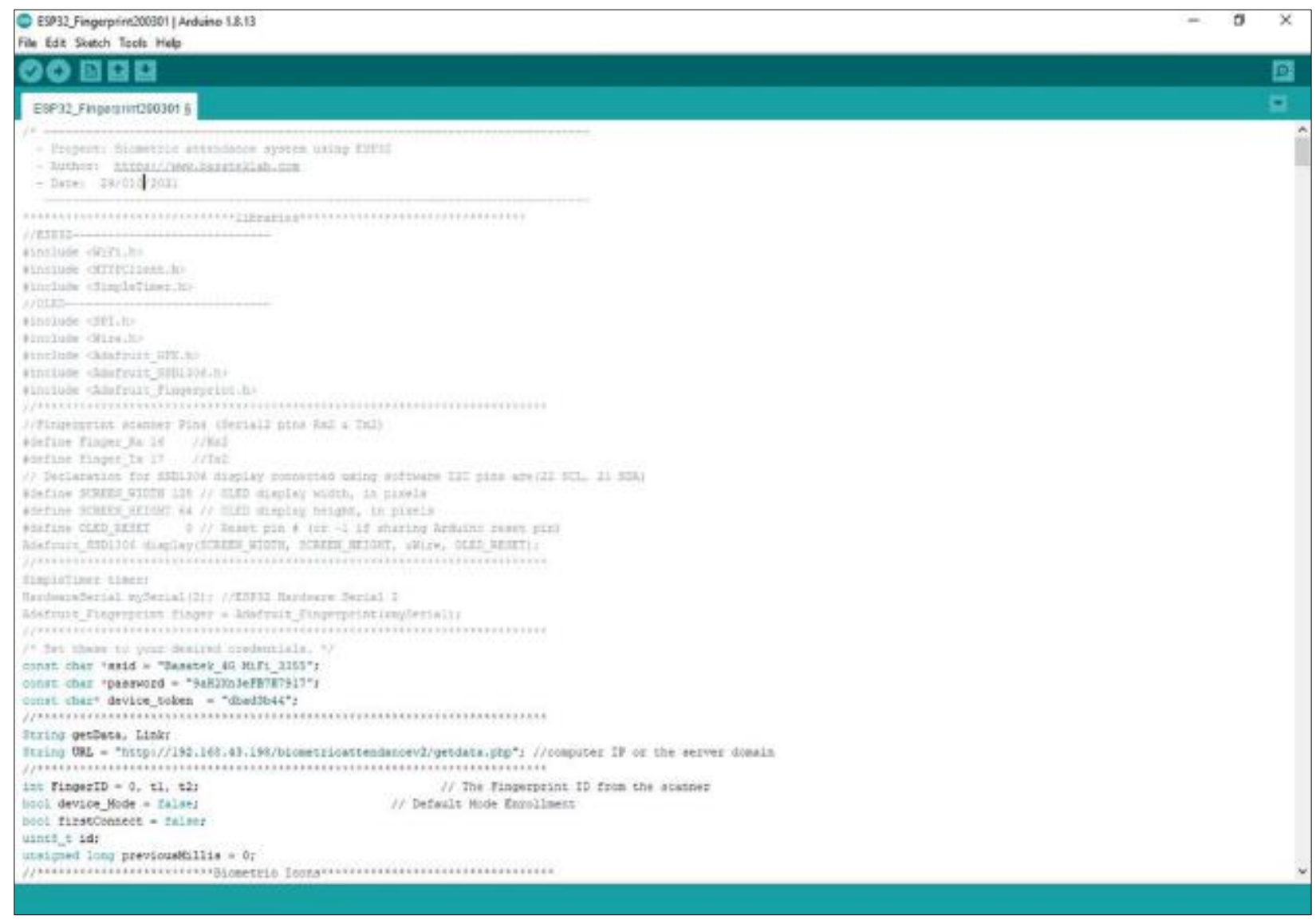

Figure 11 Arduino Integrated Development Environment 
The Firmware program was written in C using Arduino IDE. After writing and debugging of the program code, it was then compiled into a machine code using the same editor and downloaded into the ESP32 device through USB interface connected to the PC.

\section{Results}

\subsection{Testing}

Testing of the developed system is one of the paramount things that is done before putting it into use. To accomplish this, a digital multimeter is used in the testing of the circuit components to ensure that all connections were done properly. Before applying power to the circuit, the ESP module, fingerprint module and the OLED display were first removed from their respective sockets in the circuit. This was done to avoid damaging them due to either short circuit from wrong connection or PCB track during the construction procedure.

The first test was to apply power, checking that there was $+5 \mathrm{~V}$ between the power lines. Positive and negative pins of all the major components including the two power modules used in the power supply. This process was carried out with the help of a digital multimeter. After this initial test, power was then reapplied to the system to confirm that the fingerprint module OLED display comes on, with a preprogrammed message displayed to indicate that the system was working correctly and was receiving the required voltage.

\subsection{System Operation}

Turning on the system, the OLED displays the fingerprint logo, followed by intermittent blinking from the fingerprint sensor, giving the indication for user to place their finger.
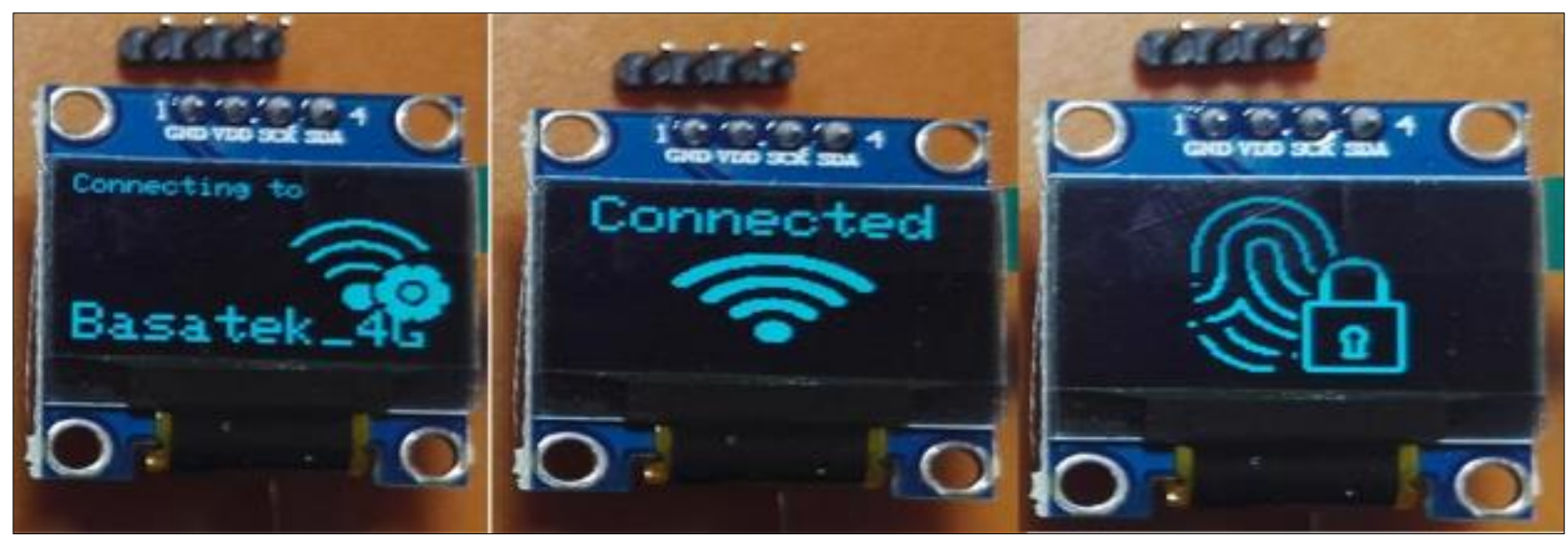

Figure 12 OLED showing System Connection

During this period, the ESP32 establishes a connection between the Wi-Fi router which was provided and configured in the program during the writing of the program code for the ESP32 device. Once it gets connected, it will displays connected on the OLED display as shown in the screen above.

\subsection{User's Registration}

The whole process of registration is straight forward. In registering user into the system, the user information (Department, Finger print ID, username, registration number and gender) is first entered into the system.

Next, the user fingerprint is taken twice, as mentioned in the datasheet and stored in EEPROM of the R305 fingerprint sensor. 


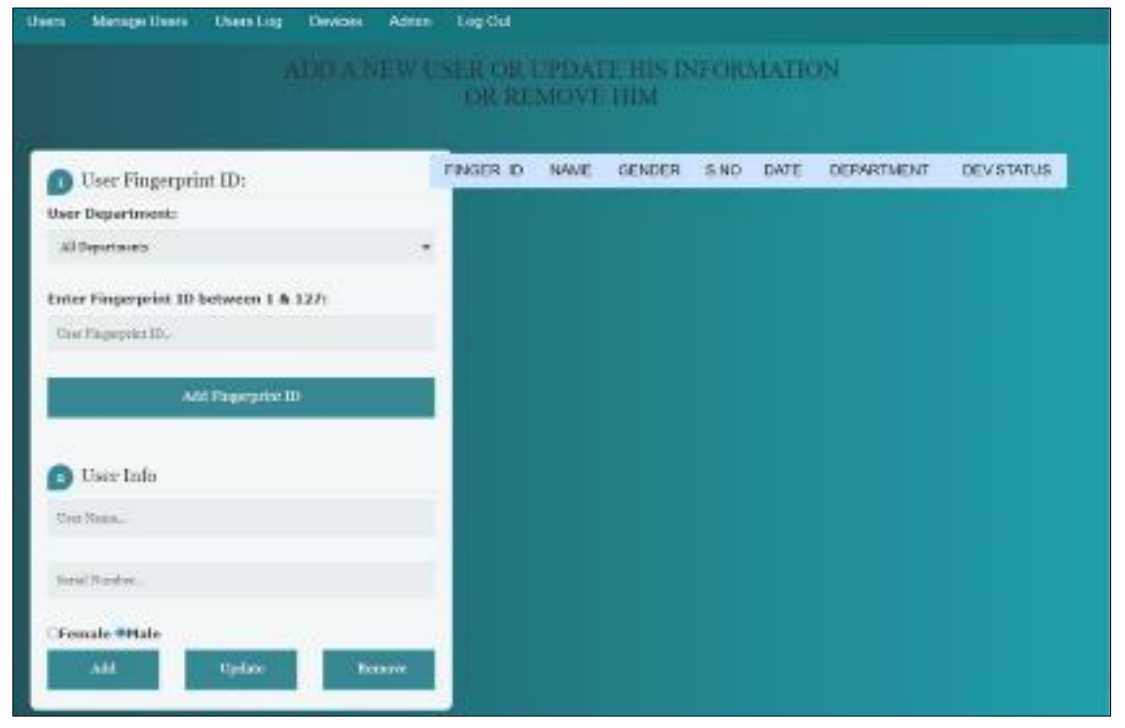

Figure 13 Registration of New User

\subsection{User's Authentication}

Once the user registration process is completed, scanning and marking of attendance begins. If a registered user scans his/her finger for the first time, it will display a welcome message. If a registered user scans his/her finger for the second time in a day, it will display the goodbye message. In a situation where the fingerprint of a user is not available or matched or an unregistered user tries to authenticate, the system will display an error message.

The entire attendance data of the students/employee can be accessed on the website by simply selecting the particular date as shown below. This data can also be downloaded in excel format by clicking on the Export to Excel button.

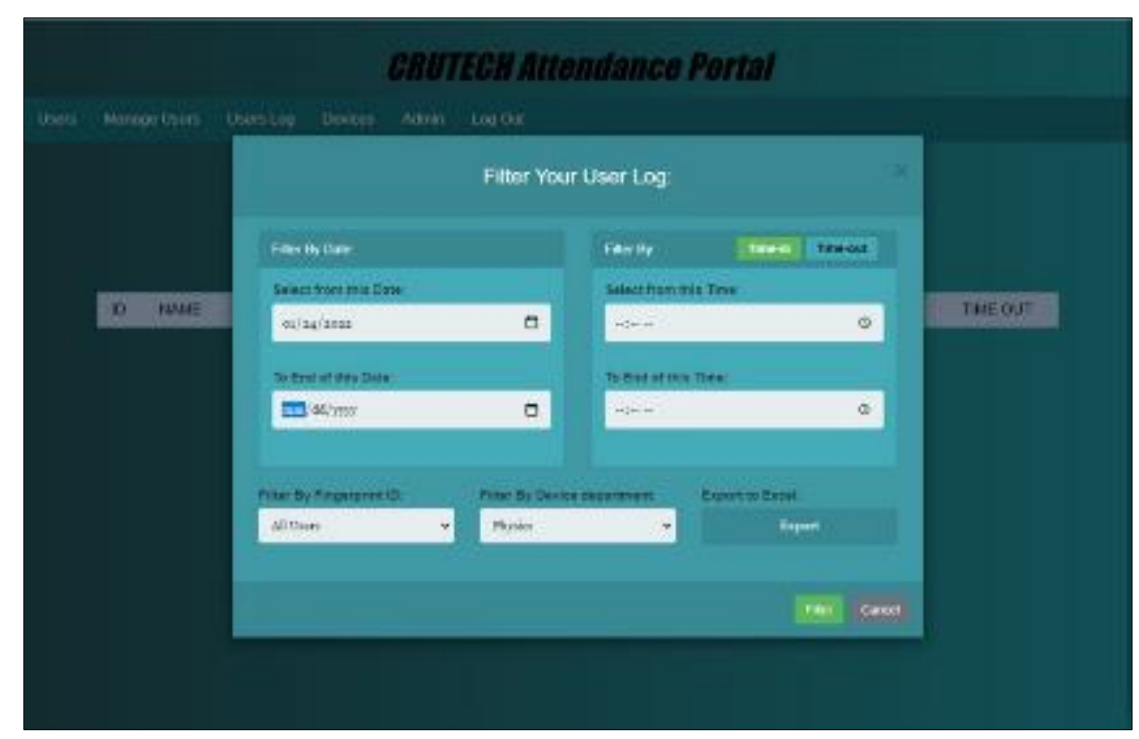

Figure 14 Authentication of User 


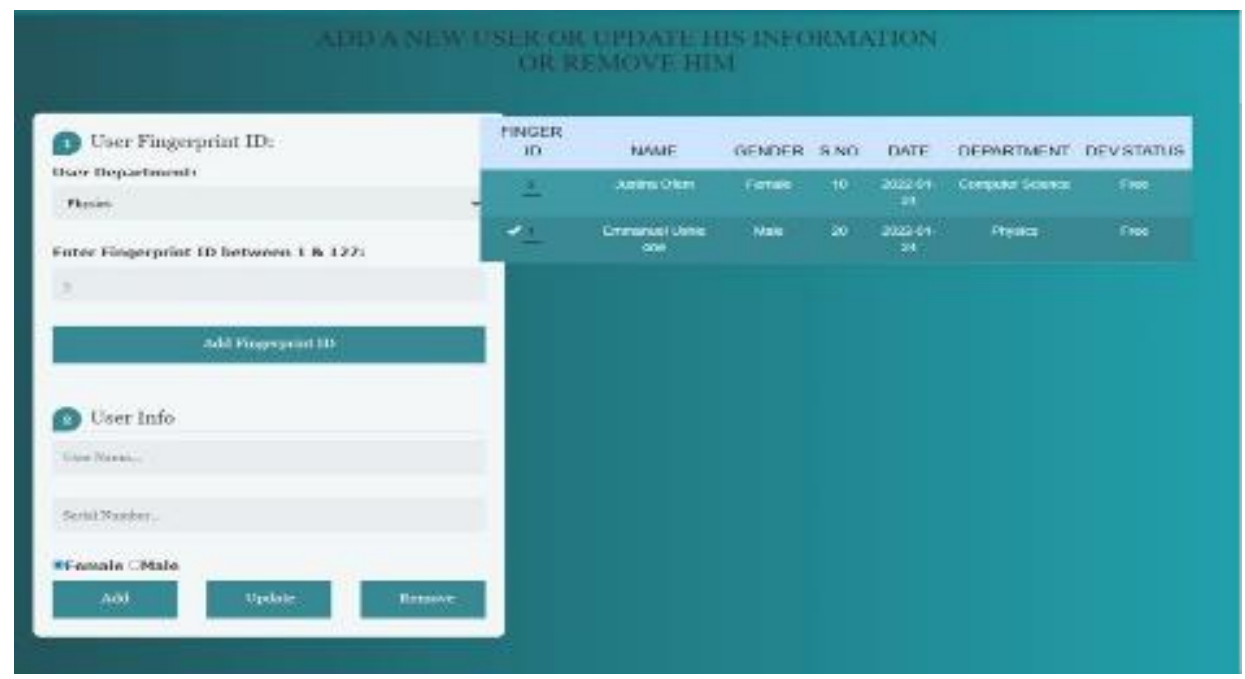

Figure 15 Attendance Data Accessed on Website

\section{Conclusion}

An IOT-Based attendance system has been developed for Cross River University of Technology, Calabar, Nigeria, with emphasis on reducing the level of fraud and data manipulation in filling the attendance list during lectures and examinations using a system of applying the concept of the Internet of Things (IoT) with the fingerprint presence method.

\section{Compliance with ethical standards}

\section{Acknowledgments}

We thank the Tertiary Education Trust Fund (TETFund) for the grant that enabled us to conduct this research.

\section{Disclosure of conflict of interest}

There was no conflict of interest in this research.

\section{References}

[1] Adeoye OS. Multi-Mode Biometric Solution for Examination Malpractices in Nigerian Schools. International Journal of Computer Applications. 2010; 4(7): 20-26.

[2] Santoso B, Sari MW. Design of Student Attendance System Using Internet of Things (IoT) Technology. J. Phys.: Conf. Ser. 2019; 1254012064.

[3] Ettah E, Ushie P, Ekah U, Eze B. The spatio-temporal distribution of noise island within the campus of Cross River University of Technology, Calabar, Nigeria. Journal of Scientific and Engineering Research. 2021; 8(6): 1-7.

[4] Emeruwa C, Ekah U. Improved algorithm of equation error model of active noise control. Journal of Multidisciplinary Engineering Science and Technology. 2022; 9(1): 15067-15072.

[5] Srivastava H. A Comparison Based Study on Biometrics for Human Recognition. IOSR Journal of Computer Engineering. 2013; 15(1): 22-29.

[6] Gagandeep, Arora J, Kumar R. Biometric fingerprint attendance system: an internet of things application, Innovations in Computer Science and Engineering. 2019; 32: 523- 530.

[7] YWM Yusof, MA Mohd Nasir, KA Othman, SI Suliman, S Shahbudin, R Mohamad. Real-time internet based attendance using face recognition system, International Journal of Engineering \& Technology. 2018; 7(3.15): 174-178. 
[8] OAR Salim, RF Olanrewaju, WA Balogun. Class attendance management system using face recognition, in 2018 7th International Conference on Computer and Communication Engineering (ICCCE). Kuala Lumpur, Malaysia. September 2018; 93-98.

[9] S Bhattacharya, GS Nainala, P Das, A Routray. Smart attendance monitoring system (SAMS): a face recognition based attendance system for classroom environment, in 2018 IEEE 18th International Conference on Advanced Learning Technologies (ICALT). Mumbai, India. July 2018; 358-360.

[10] V Soniya, SR Swetha, TK Swetha, R Ramakrishnan, S Sivakumar. Attendance automation using face recognition biometric authentication, in 2017 International Conference on Power and Embedded Drive Control (ICPEDC)., Chennai, India. March 2017; 122- 127.

[11] GJ Saxena, R Mukherjee, DK Mahato, et al. Three stage robust attendance recording and monitoring using social media platform, image processing and cloud computing, in 2017 4th International Conference on Signal Processing, Computing and Control (ISPCC). Solan, India. September 2017; 194-199.

[12] A Purohit, K Gaurav, C Bhati, A Oak. Smart attendance, in 2017 International conference of Electronics, Communication and Aerospace Technology (ICECA). Coimbatore, India. April 2017; 415-419.

[13] N Dhanalakshmi, SG Kumar, YP Sai. Aadhaar based biometric attendance system using wireless fingerprint terminals, in 2017 IEEE 7th International Advance Computing Conference (IACC). Hyderabad, India. January 2017; 651-655.

[14] DK Sarker, NI Hossain, IA Jamil. Design and implementation of smart attendance management system using multiple step authentication, in 2016 International Workshop on Computational Intelligence (IWCI). Dhaka, Bangladesh. December 2016; 91-95.

[15] S Rajkumar, J Prakash. Automated attendance using Raspberry Pi, International Journal of Pharmacy and Technology. 2016; 8(3): 16214-16221.

[16] VD Gadhave, SN Kore. Portable attendance system integrated with learning management system like moodle, in 2016 IEEE International Conference on Recent Trends in Electronics, Information \& Communication Technology (RTEICT). Bangalore, India. May 2017; 2042-2046.

[17] A Ahmed, OM Olaniyi, JG Kolo, C Durugo. A multifactor student attendance management system using fingerprint biometrics and RFID techniques, in International Conference on Information and Communication Technology and Its Applications (ICTA 2016)., Minna, Nigeria. November 2016; 69-74.

[18] Y Mittal, A Varshney, P Aggarwal, K Matani, VK Mittal. Fingerprint biometric based access control and classroom attendance management system, in 2015 Annual IEEE India Conference (INDICON). New Delhi, India. December $2016 ; 1-6$.

[19] F Mazhar, O Ahamed, M Rasedujjaman. Biometric smart attendance kit with fingerprint scanner by using microcontroller, in 2015 International Conference on Electrical \& Electronic Engineering (ICEEE). Rajshahi, Bangladesh. November 2015; 13-16.

[20] M Kamaraju, PA Kumar. Wireless fingerprint attendance management system, in 2015 IEEE International Conference on Electrical, Computer and Communication Technologies (ICECCT). Coimbatore, India. March 2015; $1-6$.

[21] MAM Said, MH Misran, MA Othman, et al. Biometric attendance, in 2014 International Symposium on Technology Management and Emerging Technologies.Bandung, Indonesia. May 2014; 258-263.

[22] S Kadry, M Smaili. Wireless attendance management system based on iris recognition, Scientific Research and Essay. 2010; 5(12): 1428-1435.

[23] NI Zainal, KA Sidek, TS Gunawan, H Manser, M Kartiwi. Design and development of portable classroom attendance system based on Arduino and fingerprint biometric, in the 5th International Conference on Information and Communication Technology for The Muslim World (ICT4M). Kuching, Malaysia, November 2014; $1-4$.

[24] BKP Mohamed, CV Raghu. Fingerprint attendance system for classroom needs, in 2012 Annual IEEE India Conference (INDICON). Kochi, India. December 2012; 433-438.

[25] JP Li, XN Zhu, X Li, ZM Zhang, JS Sui. Wireless fingerprint attendance system based on ZigBee technology, in 2010 2nd International Workshop on Intelligent Systems and Applications. Wuhan, China. May 2010; 1-4. 